\title{
A Serological Biomarker of Versican Degradation is Associated with Mortality Following Acute Exacerbations of Idiopathic Interstitial Pneumonia
}

Jannie M. B. Sand ${ }^{1 *+}$, Yoshinori Tanino ${ }^{2+}$, Morten A. Karsdal ${ }^{1}$, Takefumi Nikaido², Kenichi Misa ${ }^{2}$, Yuki Sato², Ryuichi Togawa², Xintao Wang ${ }^{2}$, Diana J. Leeming ${ }^{1}$ and Mitsuru Munakata²

\begin{abstract}
Background: Idiopathic interstitial pneumonia (IIP) is characterized by an increased rate of extracellular matrix (ECM) remodeling resulting in fibrosis. Acute exacerbations of IIP represent periods of increased disease activity, thus we hypothesized that ECM remodeling was altered during acute exacerbations and investigated this by serological neo-epitope biomarkers.

Methods: Patients who were sequentially admitted to the hospital with acute exacerbations of IIP were retrospectively analyzed for ECM remodeling at time of exacerbation (AE-IIP) and at clinical stability (S-IIP). Biomarkers released by matrix metalloproteinase-mediated degradation of collagen type I (C1M), III (C3M), IV (C4M), and $\mathrm{VI}(\mathrm{C} 6 \mathrm{M})$, elastin (ELM7), versican (VCANM), biglycan (BGM), and C-reactive protein (CRPM) were assessed in serum by competitive ELISAs utilizing neo-epitope specific monoclonal antibodies.

Results: Sixty-eight patients at AE-IIP and 29 at S-IIP were included in this retrospective analysis. Of these, 28 and 11 patients, respectively, had idiopathic pulmonary fibrosis. At AE-IIP, serum levels of C4M $(p=0.002)$ and C6M ( $p=0.024)$ were increased as compared with S-IIP, while ELM7 $(p=0.024)$ and VCANM $(p<0.0001)$ were decreased. Lower VCANM levels at AE-IIP were associated with increased risk of mortality (HR 0.64 [95\% Cl 0.43-0.94], $p=0.022$ ).

Conclusions: The ECM remodeling profile was significantly altered during acute exacerbations of IIP, and a biomarker of versican degradation was related to mortality outcome. These results indicate that biomarkers of ECM remodeling may be useful in the non-invasive evaluation of acute exacerbations of IIP. Especially versican degradation, as measured serologically by VCANM, may have prognostic potential and help guide treatment for acute exacerbations.
\end{abstract}

Keywords: Versican, Extracellular matrix, Biomarkers, Idiopathic interstitial pneumonia, Acute exacerbation

\section{Background}

Idiopathic interstitial pneumonia (IIP) is a subgroup of the diffuse parenchymal lung diseases (or interstitial lung diseases) characterized by inflammation and fibrosis of the alveolar structures [1]. This definition includes idiopathic pulmonary fibrosis (IPF), which has received special attention due to its severe nature and poor

\footnotetext{
* Correspondence: jsa@nordicbio.com

${ }^{\dagger}$ Equal contributors

${ }^{1}$ Nordic Bioscience, Biomarkers and Research, Herlev Hovedgade, 205-207

Herlev, Denmark

Full list of author information is available at the end of the article
}

prognosis [2]. An acute exacerbation of IIP is an acute, clinically significant respiratory deterioration that is associated with disease progression and high risk of mortality $[1,3]$. In IPF, up to $46 \%$ of deaths are preceded by an acute exacerbation and median survival time is as low as 3-4 months [3]. Acute exacerbations may accelerate the underlying fibrotic process, i.e. increase disease activity, and in that way contribute to disease progression. Acute exacerbations of IIP are hard to define and impossible to predict, thus diagnostic and prognostic biomarkers are needed.

(c) The Author(s). 2018 Open Access This article is distributed under the terms of the Creative Commons Attribution 4.0 International License (http://creativecommons.org/licenses/by/4.0/), which permits unrestricted use, distribution, and 
Fibrosis, a hallmark of IIP, is characterized by extracellular matrix $(\mathrm{ECM})$ deposition in the parenchyma (i.e. the interstitial matrix) and uncontrolled tissue remodeling. It results from an increased rate of ECM remodeling and a shift in the balance between protein synthesis and degradation, leading to ECM accumulation $[4,5]$. ECM remodeling results in the release of protein fragments or neo-epitopes from the tissue. These may enter the circulation where levels can be assessed by specialized ELISAs as a measure of tissue turnover [6]. We have previously shown that serological levels of neo-epitope biomarkers are associated with the presence of an acute exacerbation of chronic obstructive pulmonary disease (COPD) $[7,8]$. This indicates that rate of ECM remodeling is significantly altered during acute exacerbations of a chronic lung disease and that the group of serological neoepitope biomarkers may be reflecting acute changes in disease activity. The association with disease activity is supported by the significant association of neo-epitope biomarkers with progression and mortality of IPF shown by Jenkins et al. in the PROFILE study [9].

Versican is a member of the chondroitin sulfate/dermatan sulfate proteoglycan family and is found in the ECM of soft tissues. It consists of a core protein with attached glycosaminoglycan (GAG) chains that can be sulfated to various degrees, with the pattern affecting cellular events and chemokine binding. Versican plays an important role in tissue homeostasis and is involved in tissue repair, ECM remodeling, inflammation, infection, and cell differentiation, migration, adhesion, and proliferation. Alterations in versican expression influences ECM compliance and the permeability of vessels and airways, and thus, it may be involved in various fibroproliferative disorders. The involvement of versican in chronic obstructive pulmonary disease, asthma, and bronchiolitis obliterans syndrome have been described (reviewed in [10]), underlining the importance of versican for upholding lung structure and function.

In this study, we wanted to investigate the changes in ECM remodeling during an acute exacerbation of IIP and hypothesized that the increased disease activity associated with acute exacerbations would lead to a change in the rate of ECM degradation. This was investigated by assessing ECM remodeling by measuring neoepitopes in the circulation and evaluating their potential as biomarkers of acute exacerbations of IIP.

\section{Methods}

\section{Study Design}

This was a retrospective analysis of patients with IIP admitted to Fukushima Medical University Hospital between 2007 and 2014. All patients enrolled met the 2013 ATS/ERS Update of the International Multidisciplinary
Classification of IIP [11], and were subsequently diagnosed as having IPF or IIP other than IPF (non-IPF). IPF was diagnosed using the definition in the 2011 ATS/ ERS/JRS/ALAT joint statement [12] based on a pattern of usual interstitial pneumonia (UIP) on high resolution computed tomography (HRCT). Inclusion criteria for clinically stable IIP patients were no subjective symptoms of dyspnea or rapid deterioration on image findings for at least three months. Inclusion criteria for patients with acute exacerbation of IIP were progressive dyspnea within the last month; bilateral infiltrates or ground glass opacities on HRCT; decrease in $\mathrm{PaO}_{2} \geq 10$ Torr or $\mathrm{PaO}_{2} / \mathrm{FiO}_{2}<300 \mathrm{mmHg}$ [13]. Patients with pneumonia, heart failure, pulmonary thromboembolism, or pneumothorax were excluded, and so was patients whose progression was clearly associated with another disease. All patients included with an acute exacerbation underwent steroid pulse therapy.

The ethics committee at Fukushima Medical University approved this work (approval number 2484), and all clinical investigations were conducted according to the principles of the Declaration of Helsinki. Informed consent was not obtained as data were analyzed anonymously.

\section{Serological Biomarkers of ECM Remodeling}

Blood samples were collected from patients upon diagnosis of IIP or at presentation with an acute exacerbation. All blood samples were immediately centrifuged and serum was aliquoted and stored at $-80{ }^{\circ} \mathrm{C}$ until biomarker analysis.

ECM remodeling was evaluated in serum by specific ELISAs (Nordic Bioscience, Herlev, Denmark) according to manufacturer's instructions. Briefly, neo-epitope specific competitive ELISAs utilizing monoclonal antibodies were used to assess specific matrix metalloproteinase (MMP)-generated fragments of collagen type I (C1M [14]), III (C3M [15]), IV (C4M [16]), and VI (C6M [17]), elastin (ELM7 [18]), biglycan (BGM [19]), versican (VCANM [20]), and C-reactive protein (CRPM [21]). Reference biomarker levels were determined in a healthy population $(n=50)$ consisting of $48(96 \%)$ females and $2(4 \%)$ males with a mean age of 76 (SD 9).

\section{Statistical Analyses}

Biomarker levels at stable disease and acute exacerbations were compared by Mann-Whitney test for independent samples or Wilcoxon test for paired samples. Spearman rank correlation was used to determine associations between biomarkers and clinical parameters. Univariate and multivariate Cox regression were used to determine the relationship between biomarker levels at time of acute exacerbation and mortality outcome for the total population and the IPF subpopulation. No single parameter was found significantly associated with mortality outcome in the IPF 
subpopulation, thus, biomarker analyses were performed uncorrected. Difference in survival time between biomarker tertiles at acute exacerbation was evaluated by KaplanMeier analysis. Maximal follow-up time was set to 100 days. This analysis was not performed in subpopulations due to the low number of patients. All data analysis were performed using MedCalc Statistical Software version 16.8.4 (MedCalc Software bvba, Ostend, Belgium). All tests were two-sided at the 0.05 level of significance and all $P$ values are nominal as no adjustments were made for multiple comparisons.

\section{Results}

\section{Basic Demographics}

We included 29 patients with clinically stable IIP (S-IIP) and 68 patients with an acute exacerbation of IIP (AE-IIP). Of these, 11 and 28 patients, respectively, were diagnosed with IPF, and 28 patients had paired samples available at both clinically stable disease and at acute exacerbation. Basic demographics are summarized in Table 1. The acute exacerbation and stable groups were similar across the variables assessed with the exception of lung function measures which were significantly lower at acute exacerbation.

\section{Biomarkers at Acute Exacerbation and Stability}

At S-IIP, C3M, C4M, and VCANM serum levels were significantly correlated with age (Spearman's $\rho$ of 0.431
[ $p=0.0197], 0.401$ [ $p=0.0311]$, and -0.557 [ $p=0.0017]$, respectively). At AE-IIP, but not at S-IIP, serum C4M, $\mathrm{C} 6 \mathrm{M}$, and CRPM were significantly correlated with forced vital capacity (FVC) in percent of predicted value $(0.373$ [ $p=0.0077], 0.358$ [ $p=0.0108]$, and 0.329 [ $p=0.0197]$, respectively). Serum levels of VCANM at AE-IIP correlated significantly with survival time $(0.265$ $[p=0.0292])$.

We then compared serum levels of biomarkers of ECM remodeling at stable disease and acute exacerbations. In the total population of IIP, we found that serum levels of C4M (median 36.9 [IQR 26.4-52.0] vs. 25.8 [19. $1-37.4] \mathrm{ng} / \mathrm{mL}, p=0.0019)$ and C6M (22.9 [16.6-30.0] vs. $17.8[13.5-25.7] \mathrm{ng} / \mathrm{mL}, p=0.0235$ ) were significantly elevated at AE-IIP as compared with S-IIP (Fig. 1). Conversely, serum levels of ELM7 (2.55 [2.07-3.18] vs. $3.01[2.42-3.67] \mathrm{ng} / \mathrm{mL}, \mathrm{p}=0.0235)$ and VCANM (1.29 [1.08-1.45] vs. $1.79[1.59-2.04] \mathrm{ng} / \mathrm{mL}, \quad p<0$. 0001) were significantly decreased at AE-IIP. In the IPF subpopulation, only VCANM levels (1.34 [1.12-1. $47]$ vs. $1.84[1.66-1.97] \mathrm{ng} / \mathrm{mL}, p=0.0001)$ were significantly decreased at AE-IIP as compared with S-IIP (Fig. 1). In the paired population, C4M levels were significantly elevated at AE-IIP (36.2 [25.6-58.7] vs. 25.8 [18.8-37.5] ng/mL, $p=0.0036)$ while ELM7 (2.35 [2.05-2.93] vs. 2.99 [2.41-3.66] $\mathrm{ng} / \mathrm{mL}, p=0.0362)$, and VCANM (1.43 [1.18-1.55] vs. 1.79 [1.62-2.04] $\mathrm{ng} / \mathrm{mL}$,

Table 1 Patient characteristics

\begin{tabular}{|c|c|c|c|c|c|c|c|c|c|}
\hline & \multicolumn{3}{|c|}{ Total IIP population } & \multicolumn{3}{|c|}{ IPF subpopulation } & \multicolumn{3}{|l|}{ Paired IIP } \\
\hline & $S$ & $\mathrm{AE}$ & $p$ value & $S$ & $\mathrm{AE}$ & $p$ value & $S$ & $A E$ & $p$ value \\
\hline$n$ & 29 & 68 & & 11 & 28 & & 28 & 28 & \\
\hline Age (mean SD) & $69(8)$ & $71(7)$ & 0.206 & $67(8)$ & $71(7)$ & 0.150 & $68.3(7.6)$ & $68.3(7.6)$ & NA \\
\hline Female gender (n \%) & $6(21 \%)$ & $12(18 \%)$ & 0.726 & $0(0 \%)$ & $0(0 \%)$ & NA & $6(21 \%)$ & $6(21 \%)$ & NA \\
\hline \multicolumn{10}{|l|}{ Smokers (n \%) } \\
\hline Current & $0(0 \%)$ & $1(1 \%)$ & 0.514 & $0(0 \%)$ & $0(0 \%)$ & NA & $0(0 \%)$ & $0(0 \%)$ & NA \\
\hline Ex & 23 (79\%) & $50(74 \%)$ & 0.548 & 9 (82\%) & 23 (82\%) & 0.981 & 22 (79\%) & 22 (79\%) & \\
\hline Never & $6(21 \%)$ & 17 (25\%) & 0.649 & $2(18 \%)$ & $5(18 \%)$ & 0.981 & $6(21 \%)$ & $6(21 \%)$ & \\
\hline FVC \%pred (mean SD) & $79(27)$ & $56(19)$ & $<0.0001$ & $73(13)$ & $55(16)$ & 0.0014 & $77(26)$ & $59(24)$ & $<0.0001$ \\
\hline VC (\%pred), mean SD & $78.7(26.0)$ & $54.6(18.9)$ & $<0.0001$ & $72.7(13.5)$ & $53.6(16.0)$ & 0.0023 & $76(25)$ & $57(23)$ & $<0.0001$ \\
\hline $\begin{array}{l}\text { Time from IIP diagnosis to } \\
\text { AE admission, months } \\
\text { (median IQR) }\end{array}$ & & $12(3-38)$ & & & $29(11-40)$ & & & $24(8-38)$ & \\
\hline $\begin{array}{l}\text { Treatment duration from } \\
\text { AE admission, days } \\
\text { (median IQR) }\end{array}$ & & $8(3-14)$ & & & $7(2-12)$ & & & $8(4-16)$ & \\
\hline $\begin{array}{l}\text { Non-survivors at } 100 \text { days } \\
\text { after } A E \text { admission ( } \mathrm{n} \%)\end{array}$ & & 37 (54\%) & & & $13(46 \%)$ & & & $15(54 \%)$ & \\
\hline $\begin{array}{l}\text { Time to death after } \\
\text { AE admission, days } \\
\text { (median IQR) }\end{array}$ & & $15(6-35)$ & & & $15(4-43)$ & & & $17(10-30)$ & \\
\hline
\end{tabular}

Patient characteristics at time of stability (S) and acute exacerbation (AE) of idiopathic interstitial pneumonia (IIP) for the total population, and subpopulations of patients with idiopathic pulmonary fibrosis (IPF) or patients with paired samples (IPF $n=11$ ). S and AE were compared for each population using Mann-Whitney test, Chi squared test, or Wilcoxon test as appropriate 


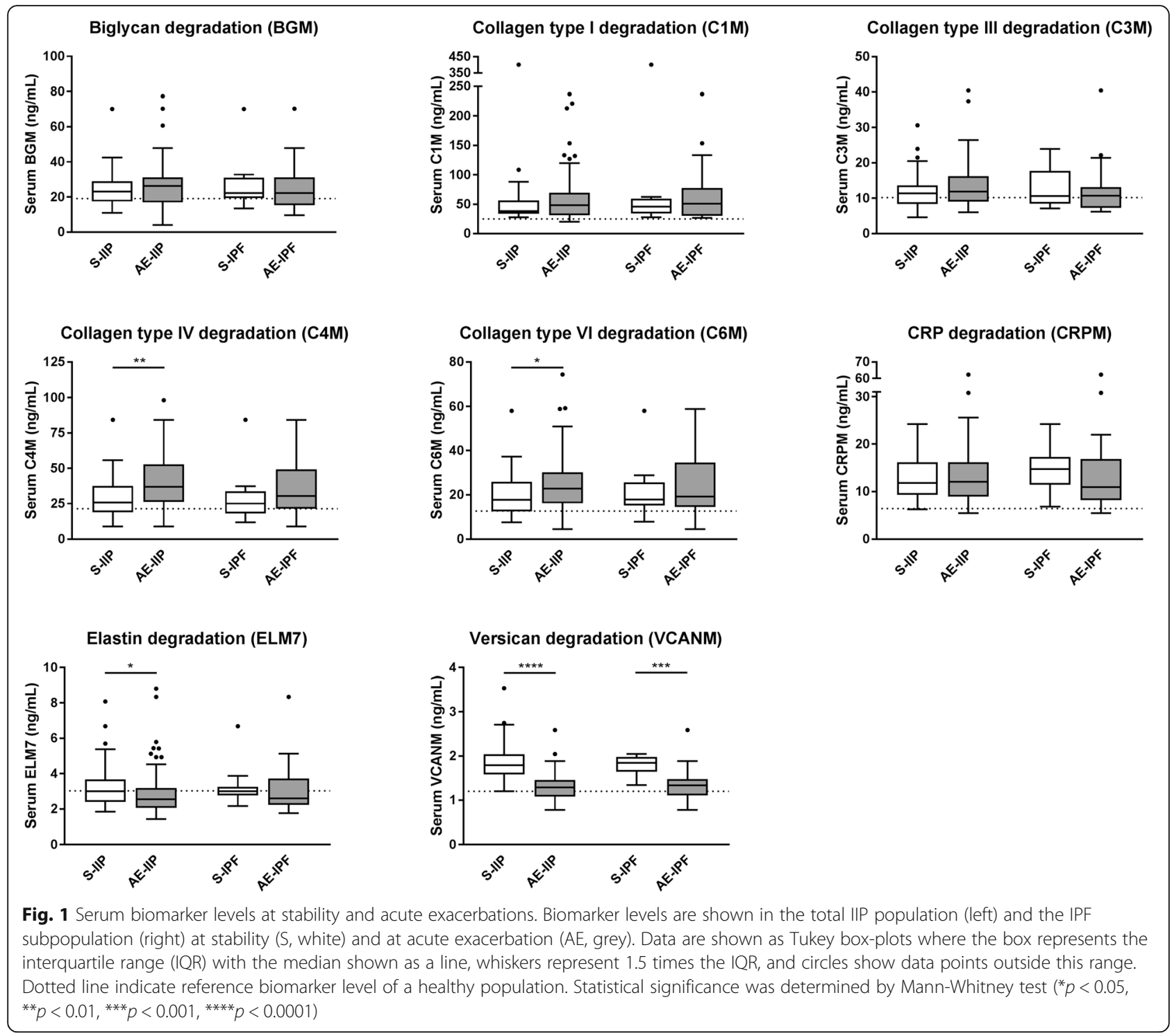

$p=0.0001)$ were significantly decreased as compared with levels at S-IIP (Fig. 2).

\section{Prediction of Mortality Following an Acute Exacerbation}

Univariate Cox regression was used to determine the clinical parameters that were related to mortality following an acute exacerbation of IIP (Table 2). Older age and female gender were significantly associated with a higher risk of mortality in IIP, but not in the IPF subpopulation, with hazard ratios of 1.059 (95\% CI 1.007-1.113; $p=0.0248)$ and 2 . 420 (95\% CI 1.166-5.025; $p=0.0177$ ), respectively. These two significant variables were included as covariates in multiple Cox regression analysis of the relationship between biomarker levels at AE-IIP and mortality outcome (Fig. 3 and Table 2). Here we found that lower levels of VCANM at AE-IIP was associated with a higher risk of mortality with a hazard ratio of 0.636 (95\% CI $0.432-0.937)$ per SD increase in serum VCANM levels $(p=0.0219)$. No biomarkers were significantly associated with mortality risk in the IPF subpopulation (Fig. 3 and Table 2). Survival times for IIP patients belonging to the different tertiles of biomarkers at AE-IIP were compared by Kaplan-Meier curves (Fig. 4). The lowest tertile of VCANM was associated with significantly shorter survival time as compared to the two higher tertiles $(p=0.0397)$.

\section{Discussion}

Here we have demonstrated for the first time that acute exacerbations of IIP are associated with acute changes in remodeling of the lung ECM and that these are related to outcome. Our main findings were: degradation of collagen type IV (C4M) and VI (C6M) was significantly elevated during an acute exacerbation of IIP as compared with stable disease, while degradation of elastin (ELM7) 


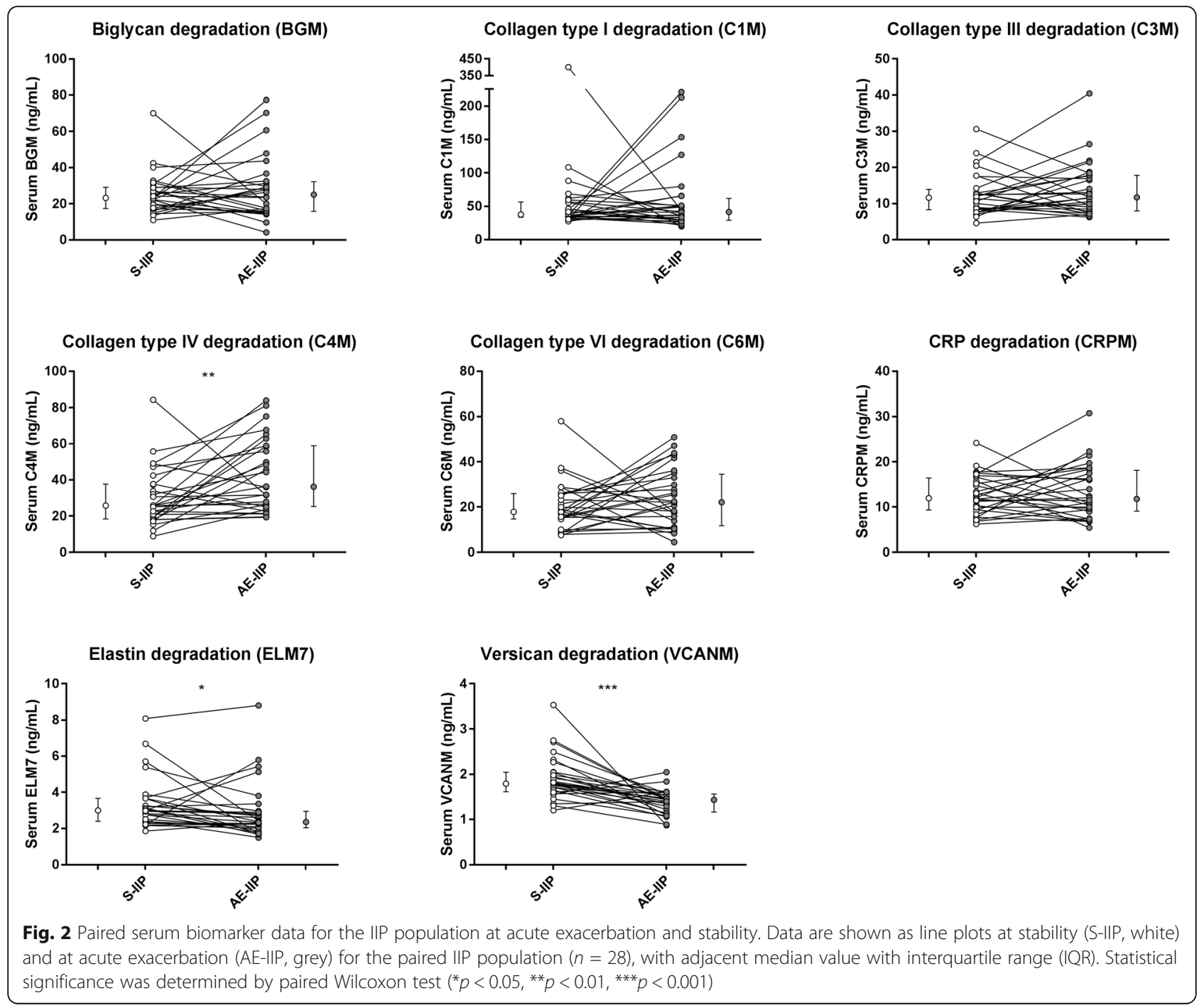

and versican (VCANM) was significantly decreased; and lower levels of versican degradation (VCANM) during an AE-IIP was significantly associated with increased risk of mortality.

Increased degree of epithelial injury during AE-IIP has previously been suggested [22] and is supported by the finding of elevated KL-6 and SP-D plasma levels in AE-IPF as compared with stable IPF [23]. In the current study, we found increased levels of C4M and $\mathrm{C} 6 \mathrm{M}$, indicating an increased rate of degradation of collagen type IV and VI during acute exacerbations. Collagen type IV is the main component of the basement membrane, located beneath the epithelial layer and collagen type VI is closely associated with the basement membrane, linking it to the interstitial matrix. Injury to the protective epithelial layer is likely to disrupt the underlying basement membrane, resulting in release of degradation fragments from collagen type IV and VI. Thus, our data support the hypothesis that epithelial injury is increased during acute exacerbations of IIP.

Serum levels of VCANM were significantly decreased during AE-IIP as compared to the stable state, indicating a potential build-up of versican in the interstitial lung tissue during an acute exacerbation. Previous results showed decreased serum levels of another proteoglycan, syndecan-4, during AE-IIP [24]. To assess syndecan-4 in serum, the transmembrane protein needs to be shed from the cell surface by MMPs and move to the bloodstream. For this to happen, the protein must undergo proteolytic processing, which could indicate that the degradation of both syndecan-4 and versican is decreased during an acute exacerbation of IIP. Increased versican deposition has been demonstrated in fibroblastic foci of IPF patients $[25,26]$ as well as in the lungs of patients with COPD [27, 28] or asthma [29], suggesting a role in the faulty repair processes related to chronic lung diseases. Serum VCANM levels at AE-IIP are 
Table 2 Clinical variables and biomarkers as predictors of mortality following acute exacerbations of IIP

\begin{tabular}{|c|c|c|c|c|}
\hline \multirow[t]{2}{*}{ Variable } & \multicolumn{2}{|l|}{ AE-IIP total population $(n=68)$} & \multicolumn{2}{|c|}{ AE-IPF subpopulation $(n=28)$} \\
\hline & $\mathrm{HR}(95 \% \mathrm{Cl})$ & $p$ value & $\mathrm{HR}(95 \% \mathrm{Cl})$ & $p$ value \\
\hline \multicolumn{5}{|l|}{ Clinical variables } \\
\hline Age & $1.059(1.007-1.113)$ & $0.025^{*}$ & $1.045(0.952-1.147)$ & 0.357 \\
\hline FVC \%pred & $0.985(0.961-1.008)$ & 0.195 & $1.023(0.991-1.057)$ & 0.164 \\
\hline Time from diagnosis to admission, months (median IQR) & $1.010(0.999-1.020)$ & 0.066 & $1.013(0.991-1.034)$ & 0.255 \\
\hline Treatment duration from admission, days (median IQR) & $0.961(0.915-1.009)$ & 0.110 & $0.940(0.856-1.031)$ & 0.187 \\
\hline Female gender & $2.420(1.166-5.025)$ & $0.018^{*}$ & NA & NA \\
\hline Ex smoker & $0.631(0.312-1.279)$ & 0.202 & $1.120(0.248-5.054)$ & 0.883 \\
\hline Current smoker & $0.000\left(5 \times e^{-191}-963 \times e^{177}\right)$ & 0.957 & NA & NA \\
\hline \multicolumn{5}{|l|}{ Biomarkers } \\
\hline BGM & $1.047(0.759-1.442)$ & 0.783 & $0.966(0.562-1.662)$ & 0.901 \\
\hline $\mathrm{C} 1 \mathrm{M}$ & $1.277(0.946-1.714)$ & 0.108 & $1.449(0.911-2.316)$ & 0.116 \\
\hline C3M & $1.010(0.722-1.412)$ & 0.955 & $0.878(0.486-1.585)$ & 0.665 \\
\hline C4M & $1.214(0.879-1.675)$ & 0.237 & $1.115(0.681-1.831)$ & 0.663 \\
\hline C6M & $1.042(0.774-1.406)$ & 0.785 & $1.160(0.702-1.915)$ & 0.564 \\
\hline CRPM & $0.959(0.707-1.304)$ & 0.792 & $0.939(0.538-1.638)$ & 0.824 \\
\hline ELM7 & $1.101(0.798-1.518)$ & 0.559 & $0.954(0.559-1.628)$ & 0.862 \\
\hline VCANM & $0.636(0.432-0.937)$ & $0.022^{*}$ & $0.828(0.446-1.538)$ & 0.551 \\
\hline
\end{tabular}

The predictive value of clinical variables for mortality following an acute exacerbation of idiopathic interstitial pneumonia (IIP, $n=68$ ) or the subpopulation of idiopathic pulmonary fibrosis (IPF, $n=28$ ) was evaluated by univariate Cox regression. The predictive value of biomarkers measured at time of acute exacerbation for mortality outcome was evaluated by multiple Cox regression adjusting for age and gender for IIP and by univariate Cox regression for IPF. Data are shown as mean hazard ratio (HR) with 95\% confidence intervals (CI). HR for biomarkers are shown per one standard deviation (SD) increase in biomarker levels at time of acute exacerbation. Asterisks indicate statistical significance $\left({ }^{*} p<0.05\right)$
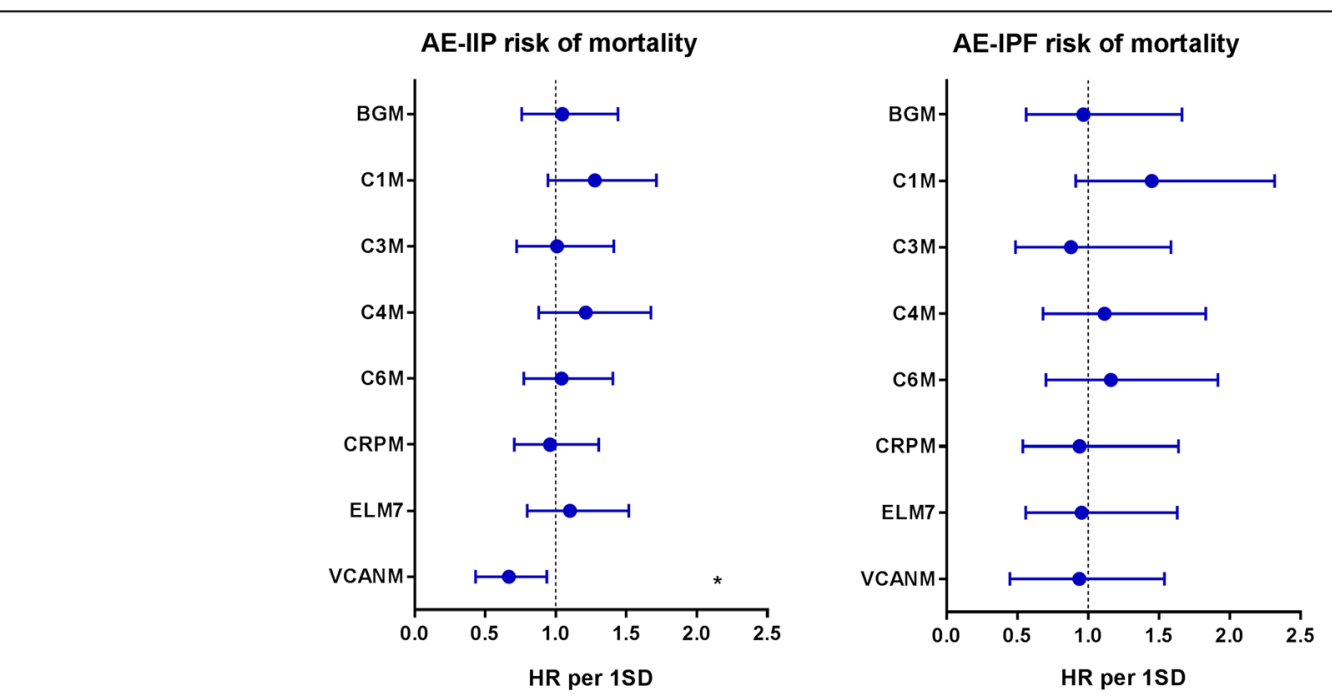

Fig. 3 Biomarkers as predictors of mortality following acute exacerbations of IIP or IPF. Cox regression analysis for mortality risk presented as hazard ratio (HR) with 95\% confidence intervals for one standard deviation (SD) increase in biomarker levels at time of acute exacerbation for the total population of IIP (left) and the subpopulation of IPF (right). HR for IIP was corrected for age and gender. Asterisks indicate statistical significance $\left.{ }^{*} p<0.05\right)$ 


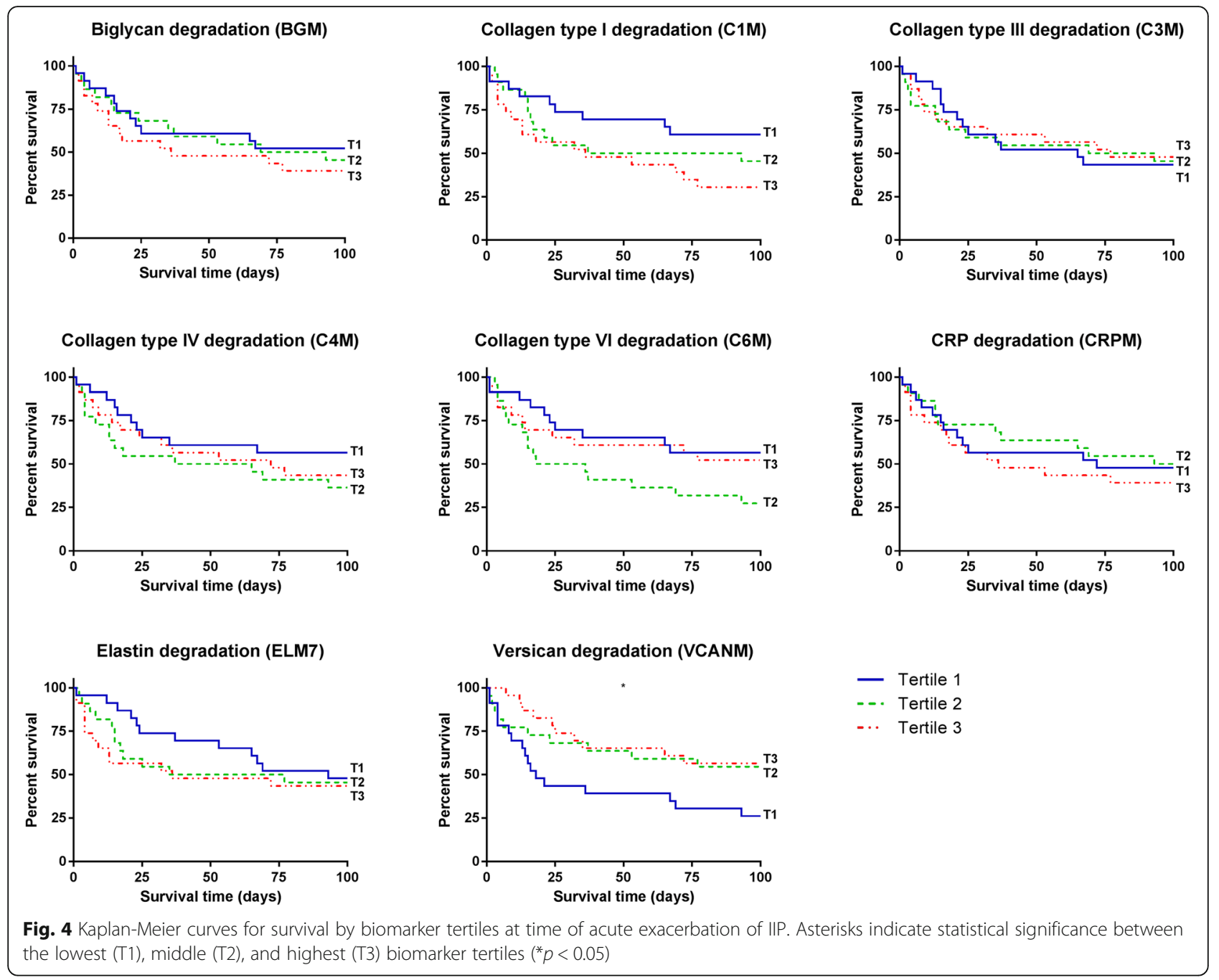

comparable to the reference level seen in a healthy, unmatched population. One could speculate that an increased rate of degradation during stable disease is an attempt to normalize the increased versican levels found in the lungs. This response might be halted temporarily while the body fights off the acute effects of an exacerbation, resulting in normal levels of versican turnover. Versican has been demonstrated to inhibit the function of elastin-binding protein, resulting in impaired formation of elastic fibers $[27,30]$. Thus, the accumulation of versican may have a negative impact on lung and vessel structure. The poorer quality of elastic fibers may lead to a decreased degradation of elastin, as indicated by lower levels of ELM7, as an attempt to prevent further loss of functioning elastic fibers.

Versican is involved in the inflammatory response, and the macrophage-derived versican expression has been found increased in response to acute inflammation [31]. IIP is a chronic condition that may show altered protein expression, whereas an acute exacerbation is an acute state of inflammation leading to a different protein expression pattern. A mouse model of acute lung injury induced by polyinosine-polycytidylic acid to mimic a viral infection has shown accumulation of versican in the lung. Furthermore, versican knock-out mice had an attenuated proinflammatory response [32]. These data could indicate that versican may build up in the lungs during acute exacerbations of chronic lung diseases, which is in line with a decrease in its degradation seen in the present study. Additionally, a decrease in versican degradation has also been associated with acute exacerbations of COPD [7].

The major limitations to this study are related to the retrospective nature of the study design and the heterogeneous study population. The diagnosis of IIP includes different fibrotic lung diseases, which may introduce a greater variation in the present data. We have diagnosed patients with an UIP pattern on HRCT as having IPF using the definition in the 2011/ATS/ERS/JRS/ALAT joint statement. Because surgical lung biopsy was not 
performed, a histopathological analysis to confirm the UIP pattern was not possible, and the non-IPF patients in the current study represents a heterogeneous population. It has been debated whether a possible UIP pattern on HRCT is sufficient to make a diagnosis of IPF [3335 ], and one study found $23 \%$ of patients with HRCT findings inconsistent with the UIP pattern to have a definite/probable UIP pattern on biopsy. Although idiopathic non-specific interstitial pneumonia (NSIP) might be the major type of IIP in the non-IPF group in the present study, it is possible that other IIPs such as IPF and unclassifiable IIPs were included. As a definite diagnosis could not be made in the non-IPF patients, subgroup analysis was only performed for the IPF group. Future studies should include more patients and perform subgroup analysis on IPF and NSIP to evaluate if ECM remodeling differs between these patient groups. Another limitation to this study is the inclusions of patients with unpaired samples or paired samples taken far apart. We have compared baseline characteristics for all patients to investigate the effect of inter-patient variation in the total population, IPF only as well as for patients with paired samples. Only lung function differed significantly between stable disease and time of exacerbations, indicating that the included patients were comparable as lung function is expected to be affected by an acute exacerbation. However, it cannot be ruled out that a lower lung function during acute exacerbation may be related to a permanent change and thus disease progression. We compared unpaired samples and subsequently confirmed the findings for C4M, ELM7 and VCANM using paired samples. Only the association with C6M could not be confirmed using paired samples. For patients with paired samples, the follow-up time between stable disease and acute exacerbation was long which may have influenced the disease progression and activity.

\section{Conclusion}

In conclusion, our data indicate that acute exacerbations of IIP are associated with degradation of the basement membrane and a build-up of versican and elastin in the interstitial matrix of the lung, as determined by serological neo-epitope specific biomarkers. The difference in degradation profile for the proteins studied is intriguing and indicate activation of different processes contributing to AE-IIP. Furthermore, the potential build-up of versican indicated by lower levels of VCANM, a biomarker reflecting versican degradation, is associated with increased risk of mortality. Thus, serological neo-epitope biomarkers reflecting lung ECM remodeling may be useful tools in the noninvasive assessment of acute exacerbations of IIP, and VCANM may represent a novel prognostic biomarker.
However, the current data should be validated in separate cohorts to evaluate the potential use.

\section{Abbreviations \\ AE-IIP: Acute exacerbation of idiopathic interstitial pneumonia; BGM: Biglycan degraded by MMPs; C1M: Collagen type I degraded by MMPs; C3M: Collagen type III degraded by MMPs; C4M: Collagen type IV degraded by MMPs; C6M: Collagen type VI degraded by MMPs; COPD: Chronic obstructive pulmonary disease; CRPM: C-reactive protein degraded by MMPs; \\ ECM: Extracellular matrix; ELM7: Elastin degraded by MMP7; FVC: Forced vital capacity; GAG: Glycosaminoglycan; HRCT: High resolution computed tomography; IIP: Idiopathic interstitial pneumonia; IPF: Idiopathic pulmonary fibrosis; IQR: Interquartile range; MMP: Matrix metalloproteinase; NSIP: Non- specific interstitial pneumonia; S-IIP: Clinically stable idiopathic interstitial pneumonia; VCANM: Versican degraded by MMPs}

\section{Funding}

This study was funded by the Danish Research Foundation and was supported in part by a grant to the Diffuse Lung Diseases Research Group from the Ministry of Health, Labour and Welfare, Japan.

Availability of Data and Materials

The datasets used and/or analyzed during the current study are available from the corresponding author on reasonable request.

\section{Authors' Contributions}

JMBS and YT designed the study. JMBS drafted the manuscript and had primary responsibility for data analysis. All authors contributed to data acquisition and/or interpretation, revised and approved the final manuscript.

\section{Ethics Approval and Consent to Participate}

The ethics committee at Fukushima Medical University approved this work (approval number 2484), and all clinical investigations were conducted according to the principles of the Declaration of Helsinki. Informed consent was not obtained as data were analyzed anonymously.

\section{Competing Interests}

JMBS, MAK and DJL are employed by Nordic Bioscience, and MAK and DJL hold stocks. YT, TN, KM, YS, RT, XW and MM have reported no conflicts of interest.

\section{Publisher's Note}

Springer Nature remains neutral with regard to jurisdictional claims in published maps and institutional affiliations.

\section{Author details}

${ }^{1}$ Nordic Bioscience, Biomarkers and Research, Herlev Hovedgade, 205-207 Herlev, Denmark. 'Department of Pulmonary Medicine, Fukushima Medical University, Fukushima, Japan.

Received: 20 December 2017 Accepted: 16 April 2018

Published online: 04 May 2018

\section{References}

1. Travis WD, Costabel U, Hansell DM, King TE, Lynch DA, Nicholson AG, et al. An official American Thoracic Society/European Respiratory Society statement: update of the international multidisciplinary classification of the idiopathic interstitial pneumonias. Am J Respir Crit Care Med. 2013;188:73348. https://doi.org/10.1164/rccm.201308-1483ST.

2. Daccord C, Maher TM. Recent advances in understanding idiopathic pulmonary fibrosis. F1000Research. 2016;5:1-13. https://doi.org/10.12688/ f1000research.8209.1.

3. Collard HR, Ryerson CJ, Corte TJ, Jenkins G, Kondoh Y, Lederer DJ, et al. Acute exacerbation of idiopathic pulmonary fibrosis an international working group report. Am J Respir Crit Care Med. 2016;194:265-75. https:// doi.org/10.1164/rccm.201604-0801Cl.

4. Rockey DC, Bell PD, Hill JA. Fibrosis - a common pathway to organ injury and failure. N Engl J Med. 2015;372:1138-49. https://doi.org/10.1056/ NEJMra1300575.

5. Wynn TA, Ramalingam TR. Mechanisms of fibrosis: therapeutic translation for fibrotic disease. Nat Med. 2012;18:1028-40. https://doi.org/10.1038/nm.2807. 
6. Karsdal MA, Nielsen MJ, Sand JM, Henriksen K, Genovese F, Bay-Jensen A-C, et al. Extracellular matrix remodeling: the common denominator in connective tissue diseases. Possibilities for evaluation and current understanding of the matrix as more than a passive structure, but a key player in tissue failure. Assay Drug Dev Technol. 2013;11:70-92. https://doi. org/10.1089/adt.2012.474

7. Sand JMB, Knox AJ, Lange P, Sun S, Kristensen JH, Leeming DJ, et al. Accelerated extracellular matrix turnover during exacerbations of COPD. Respir Res. 2015;16:69. https://doi.org/10.1186/s12931-015-0225-3.

8. Stolz D, Leeming DJ, Kristensen JHE, Karsdal MA, Boersma W, Louis R, et al. Systemic biomarkers of collagen and elastin turnover are associated with clinically relevant outcomes in COPD. Chest. 2017;151:47-59. https://doi.org/ 10.1016/j.chest.2016.08.1440.

9. Jenkins RG, Simpson JK, Saini G, Bentley JH, Russell AM, Braybrooke R, et al. Longitudinal change in collagen degradation biomarkers in idiopathic pulmonary fibrosis: an analysis from the prospective, multicentre PROFILE study. Lancet Respir Med. 2015;3:462-72. https://doi.org/10.1016/S22132600(15)00048-X.

10. Andersson-Sjöland A, Hallgren O, Rolandsson S, Weitoft M, Tykesson E, Larsson-Callerfelt AK, et al. Versican in inflammation and tissue remodeling: the impact on lung disorders. Glycobiology. 2015;25:243-51. https:/doi.org/ 10.1093/glycob/cwu120.

11. Sgalla G, Biffi A, Richeldi L. Idiopathic pulmonary fibrosis: diagnosis, epidemiology and natural history. Respirology. 2016;21:427-37. https://doi. org/10.1111/resp.12683.

12. Raghu G, Collard HR, Egan JJ, Martinez FJ, Behr J, Brown KK, et al. An official ATS/ERS/JRS/ALAT statement: idiopathic pulmonary fibrosis: evidence-based guidelines for diagnosis and management. Am J Respir Crit Care Med. 2011; 183:788-824. https://doi.org/10.1164/rccm.2009-040GL.

13. Inokoshi $Y$, Tanino $Y$, Wang $X$, Sato S, Fukuhara N, Nikaido T, et al. Clinical significance of serum hyaluronan in chronic fibrotic interstitial pneumonia. Respirology. 2013;18:1236-43. https://doi.org/10.1111/resp.12144.

14. Leeming D, He Y, Veidal S, Nguyen Q, Larsen D, Koizumi M, et al. A novel marker for assessment of liver matrix remodeling: an enzyme-linked immunosorbent assay (ELISA) detecting a MMP generated type I collagen neo-epitope (C1M). Biomarkers. 2011;16:616-28. https://doi.org/10.3109/ 1354750X.2011.620628.

15. Veidal SS, Vassiliadis E, Barascuk N, Zhang C, Segovia-Silvestre T, Klickstein L, et al. Matrix metalloproteinase-9-mediated type III collagen degradation as a novel serological biochemical marker for liver fibrogenesis. Liver Int. 2010;30: 1293-304. https://doi.org/10.1111/j.1478-3231.2010.02309.x.

16. Sand JM, Larsen L, Hogaboam C, Martinez F, Han M, Røssel Larsen M, et al. MMP mediated degradation of type IV collagen alpha 1 and alpha 3 chains reflects basement membrane remodeling in experimental and clinical fibrosis-validation of two novel biomarker assays. PLoS One. 2013;8:e84934. https://doi.org/10.1371/journal.pone.0084934.

17. Veidal SS, Karsdal MA, Vassiliadis E, Nawrocki A, Larsen MR, Nguyen QHT, et al. MMP mediated degradation of type VI collagen is highly associated with liver fibrosis - identification and validation of a novel biochemical marker assay. PLoS One. 2011;6:1-9. https:/doi.org/10.1371/journal.pone.0024753.

18. Kristensen JH, Larsen L, Dasgupta B, Brodmerkel C, Curran M, Karsdal MA et al. Levels of circulating MMP-7 degraded elastin are elevated in pulmonary disorders. Clin Biochem. 2015;48:1083-8. https://doi.org/10.1016/ j.clinbiochem.2015.07.009.

19. Genovese F, Barascuk N, Larsen L, Larsen MR, Nawrocki A, Li Y, et al. Biglycan fragmentation in pathologies associated with extracellular matrix remodeling by matrix metalloproteinases. Fibrogenesis Tissue Repair. 2013;6: 9. https://doi.org/10.1186/1755-1536-6-9.

20. Barascuk N, Genovese F, Larsen L, Byrjalsen I, Zheng Q, Sun S, et al. A MMP derived versican neo-epitope is elevated in plasma from patients with atherosclerotic heart disease. Int J Clin Exp Med. 2013;6:174-84.

21. Skjøt-Arkil H, Schett G, Zhang C, Larsen DV, Wang Y, Zheng Q, et al. Investigation of two novel biochemical markers of inflammation, matrix metalloproteinase and cathepsin generated fragments of C-reactive protein, in patients with ankylosing spondylitis. Clin Exp Rheumatol. 2012;30:371-9.

22. Antoniou KM, Wells AU. Acute exacerbations of idiopathic pulmonary fibrosis. Respiration. 2013;86:265-74. https://doi.org/10.1159/000355485.

23. Collard HR, Calfee CS, Wolters PJ, Song JW, Hong S-B, Brady S, et al. Plasma biomarker profiles in acute exacerbation of idiopathic pulmonary fibrosis. AJP Lung Cell Mol Physiol. 2010;299:L3-7. https://doi.org/10.1152/ajplung. 90637.2008.
24. Sato $Y$, Tanino $Y$, Wang $X$, Nikaido $T$, Sato $S$, Misa $K$, et al. Baseline serum syndecan-4 predicts prognosis after the onset of acute exacerbation of idiopathic interstitial pneumonia. PLoS One. 2017;12:1-16. https://doi.org/10. 1371/journal.pone.0176789.

25. Bensadoun ES, Burke AK, Hogg JC, Roberts CR. Proteoglycan deposition in pulmonary fibrosis. Am J Respir Crit Care Med. 1996;154:1819-28. https:// doi.org/10.1164/ajrccm.154.6.8970376.

26. Estany S, Vicens-Zygmunt V, Llatjós R, Montes A, Penín R, Escobar I, et al. Lung fibrotic tenascin-C upregulation is associated with other extracellular matrix proteins and induced by TGF $\beta 1$. BMC Pulm Med. 2014;14:120. https://doi.org/10.1186/1471-2466-14-120.

27. Merrilees MJ, Ching PST, Beaumont B, Hinek A, Wight TN, Black PN. Changes in elastin, elastin binding protein and versican in alveoli in chronic obstructive pulmonary disease. Respir Res. 2008;9:41. https://doi.org/10. 1186/1465-9921-9-41.

28. Hallgren O, Nihlberg K, Dahlbäck M, Bjermer L, Eriksson LT, Erjefält JS, et al. Altered fibroblast proteoglycan production in COPD. Respir Res. 2010;11:55. https://doi.org/10.1186/1465-9921-11-55.

29. Nihlberg K, Andersson-Sjoland A, Tufvesson E, Erjefalt JS, Bjermer L, Westergren-Thorsson G. Altered matrix production in the distal airways of individuals with asthma. Thorax. 2010;65:670-6. https://doi.org/10.1136/thx. 2009.129320.

30. Huang R, Merrilees MJ, Braun K, Beaumont B, Lemire J, Clowes AW, et al. Inhibition of versican synthesis by antisense alters smooth muscle cell phenotype and induces elastic fiber formation in vitro and in neointima after vessel injury. Circ Res. 2006;98:370-7. https://doi.org/10.1161/01.RES. 0000202051.28319.c8.

31. Chang MY, Tanino Y, Vidova V, Kinsella MG, Chan CK, Johnson PY, et al. Reprint of: a rapid increase in macrophage-derived versican and hyaluronan in infectious lung disease. Matrix Biol. 2014;35:162-73. https://doi.org/10. 1016/j.matbio.2014.04.003.

32. Kang I, Harten IA, Chang MY, Braun KR, Sheih A, Nivison MP, et al. Versican deficiency significantly reduces lung inflammatory response induced by polyinosine-polycytidylic acidstimulation. J Biol Chem. 2017;292:51-63. https://doi.org/10.1109/JPHOT.2016.2639045.

33. Raghu G, Lynch D, Godwin JD, Webb R, Colby TV, Leslie KO, et al. Diagnosis of idiopathic pulmonary fibrosis with high-resolution $\mathrm{CT}$ in patients with little or no radiological evidence of honeycombing: secondary analysis of a randomised, controlled trial. Lancet Respir Med. 2014;2:277-84. https://doi. org/10.1016/S2213-2600(14)70011-6.

34. Chung JH, Chawla A, Peljto AL, Cool CD, Groshong SD, Talbert JL, et al. CT scan findings of probable usual interstitial pneumonitis have a high predictive value for histologic usual interstitial pneumonitis. Chest. 2015;147: 450-9. https://doi.org/10.1378/chest.14-0976.

35. Brownell R, Moua T, Henry TS, Elicker BM, White D, Vittinghoff E, et al. The use of pretest probability increases the value of high-resolution CT in diagnosing usual interstitial pneumonia. Thorax. 2017;72:424-9. https://doi. org/10.1136/thoraxjnl-2016-209671.

\section{Ready to submit your research? Choose BMC and benefit from:}

- fast, convenient online submission

- thorough peer review by experienced researchers in your field

- rapid publication on acceptance

- support for research data, including large and complex data types

- gold Open Access which fosters wider collaboration and increased citations

- maximum visibility for your research: over $100 \mathrm{M}$ website views per year

At BMC, research is always in progress.

Learn more biomedcentral.com/submissions 